\section{Co-overexpression of bcl-2 and c-myc in uterine cervix carcinomas and premalignant lesions}

\author{
Z. Protrka, ${ }^{1}$ S. Arsenijevic, ${ }^{1}$ \\ A. Dimitrijevic, ${ }^{1}$ S. Mitrovic, ${ }^{2}$ \\ V. Stankovic, ${ }^{2}$ M. Milosavljevic, ${ }^{2}$ \\ T. Kastratovic, ${ }^{1}$ J. Djuric ${ }^{1}$ \\ 'Department of Obstetrics and \\ Gynecology, Faculty of Medicine, \\ University of Kragujevac; \\ 2Department of Pathology, Faculty \\ of Medicine, University of Kragujevac, \\ Serbia
}

\section{Abstract}

To establish the role of co-overexpression of bcl-2 and c-myc protooncogenes in uterine cervix carcinogenesis, we examined 138 tissue samples of low grade cervical squamous intraepithelial lesions (SIL), high grade SIL, portio vaginalis uteri (PVU) carcinoma in situ and PVU invasive carcinoma, stage IA-IIA (study group) and 36 samples without SIL or malignancy (control group). The expression of bcl-2 and c-myc was detected immunohistochemically using a monoclonal antibody. Fisher's exact test $(\mathrm{P}<0.05)$ was used to assess statistical significance. Overexpression of bcl-2 was found to increase in direct relation to the grade of the cervical lesions. High sensitivity was of great diagnostic significance for the detection of these types of changes in the uterine cervix. On the basis of high predictive values it can be said that in patients with bcl-2 overexpression there is a great possibility that they have premalignant or malignant changes in the uterine cervix. Cooverexpression of bcl-2 and c-myc oncogenes was found only in patients with PVU invasive carcinoma (6/26-23.0\%). Statistically significant difference was not found in the frequency of cooverexpression in patients with PVU invasive carcinoma in relation to the control group (Fisher's test; $\mathrm{P}=0.064$ ). The method's sensitivity of determining these oncogenes with the aim of detecting PVU invasive carcinoma was 23\%, while specificity was $72.2 \%$. On the basis of high predictive values (100\%), speaking in statistical terms, it can be concluded that all patients with co-overexpression of bcl-2 and c-myc oncogenes will have PVU invasive carcinoma. We confirmed in our research that co-overexpression of bcl-2 and c-myc oncogenes was increased only in PVU invasive carcinoma. However, a more extensive series of samples and additional tests are required to establish the prognostic significance of bcl-2 and c-myc co-overexpression in cervical carcinogenesis.

\section{Introduction}

Squamous cell carcinoma of the uterine cervix is currently one of the most common malignancies in women worldwide. In searching ways of prevention, early diagnosis and effective treatment of premalignant lesions and malignant tumors of the uterine cervix, molecular-genetic researches played a significant role in the last few years.

Alterations at the genetic or protein level of the protooncogenes result in oncogenic conversion and impaired cellular growth control mechanisms, causing tumor development. ${ }^{1}$

Analysis of oncogenes expression in human cancer is increasingly important to gain a better insight in the process of tumorigenesis and identify new markers for early diagnosis of malignant transformation. Abnormal expression of different cellular oncogenes in various cancers assessed by hybridization and immunological techniques has been previously reported. ${ }^{2}$ The results of these analyses do not appear to be of any early diagnostic value since oncogene expression is, in general, only demonstrable in tumors that can already be classified as malignant.

The key difference between normal and malignant cell is in a subtle change of specific genes that control, by their products, the processes of growth, division and differentiation of a cell and are called protooncogenes. These genes that are present in the genotype of every normal cell possess the oncogenic potential because their disturbed expression may lead to malignant transformation.

The bcl-2 family of related proteins is one of the key regulators of the apoptotic process. It consists of two opposing groups of proteins: death antagonists (bcl-2, bcl-XL, Mcl-1) and death agonists (bax, bak, bcl-XS). ${ }^{3}$ Apoptosis occurs through competing dimerization between the two protein groups. The relative proportions of which ultimately control the sensitivity or resistance of cells to apoptotic stimuli. Overexpression of bcl- 2 and bax and their prognostic significance have been reported in several epithelial cancers. ${ }^{4}$ However, the data on squamous cell carcinoma of the uterine cervix are limited and the results are conflicting. ${ }^{2,5}$ In vitro studies have also shown that bcl-2 overexpression prolonged cell survival in cell culture studies. ${ }^{6}$ Therefore, an in vivo study on the association between these apoptosis regulatory proteins may be a prerequisite for the complete understanding of the molecular pathogenesis underlying cervical cancer development.

Mitochondrial and cell-surface death receptor-mediated apoptosis are the two principal pathways leading to programmed cell death. The mitochondrial pathway is thought to play a
Correspondence: Dr. Zoran Protrka, Department of Obstetrics and Gynecology, Faculty of Medicine, University of Kragujevac, Stevana Visokog 28, 34000 Kragujevac, Serbia. Tel. + 381.34.6342482 - Fax: +381.34 .370168 . E-mail: protrka.zoran@gmail.com

Key words: bcl-2, c-myc, carcinogenesis, cervical neoplasia, immunohistochemistry.

Received for publication: 24 November 2010. Accepted for publication: 16 February 2011.

This work is licensed under a Creative Commons Attribution 3.0 License (by-nc 3.0).

(C) Copyright Z. Protrka et al., 2011 Licensee PAGEPress, Italy

European Journal of Histochemistry 2011; 55:e8 doi:10.4081/ejh.2011.e8

major role in response to cancer treatments and is mediated by the bcl- 2 family proteins. ${ }^{7}$ More than 20 members of this family have been described so far in humans. A positive ratio between pro- and antiapoptotic bcl-2 family members leads to cytochrome-C release from mitochondria, which triggers the final execution of cell death by the caspase cascade.

The c-myc gene belongs to the myc family that includes b-myc, l-myc, n-myc and s-myc. However, only c-myc, l-myc and n-myc have neoplastic potential. ${ }^{8}$ The ability of myc to promote cell proliferation indicates that its deregulation leads to deregulated DNA synthesis and genomic instability. ${ }^{9}$ Deregulated myc expression is linked to increasing in both cyclin A and cyclin E levels. ${ }^{10}$ In vitro and in vivo data indicate that increased expression of c-myc blocks differentiation and enhances proliferative and apoptotic activity. ${ }^{11}$ Chlamydia trachomatis and HPV high-risk types may contribute to neoplastic changes in the transformation of the uterine cervix and also might modulate expression of c-myc oncogene. ${ }^{12}$

Overexpression of c-myc was frequently found in advanced stages of cervical cancers and was shown to be associated with tumor progression. ${ }^{13,14}$ Moreover, it has been shown in experimental tumor systems that increased expression of bcl-2 and c-myc can cooperate in tumorigenesis. $^{14,15}$

\section{Materials and Methods}

This prospective study was carried out during 2008 and 2009, at the Department of Obstetrics and Gynecology, Faculty of Medicine and the experimental part was performed at the Laboratory for Experimental and Clinical Immunology of the Faculty of Medicine and at 
the Immunological Laboratory of the Public Health Institute, Kragujevac, Serbia. From patients operated at the Department of Obstetrics and Gynecology because of premalignant and/or malignant changes of the uterine cervix, some tissue sections were taken from the operative material (hysterectomy, punch biopsy or conization) for pathological verification and used for this research. The control group consisted of 36 females in whom ambulatory biopsy of the uterine cervix was performed (Papanicolaou test was indicated) and where malignant changes or squamous intraepithelial lesions (SIL) were not found by histopathology (cervicitis chronica of mild to moderate degree). The study group consisted of 32 patients with the pathological diagnosis of low grade SIL, 22 with high grade SIL, 22 with PVU carcinoma in situ and 26 with PVU invasive carcinoma, stage IA-IIA. Bcl-2 and cmyc oncogene expression followed in patients in the study and the control group. Co-overexpression of this oncogene was observed as the way of detection of premalignant and malignant changes in the uterine cervix. Cryostat sections were sent for intraoperative diagnosis. Extra sections of cervical lesions were snap-frozen in liquid nitrogen and stored at $-70^{\circ} \mathrm{C}$ until used for immunohistochemistry.

Bcl-2 (Anti-Bcl-2 $\alpha$ (Ab-1) Mouse mAb (100/D5), Calbiochem, Oncogene Research, Cambridge, MA, USA) and c-myc (Anti-c-Myc (Ab-1) Mouse mAb (9E10), Calbiochem) monoclonal antibody was used, which was diluted with phosphate buffered saline (PBS, pH 7.2).

Four-micrometer frozen sections were fixed in $100 \%$ acetone for $5 \mathrm{~min}$ and the endogenous peroxidase activity was quenched by $10 \mathrm{~min}$ incubation in $0.5 \%$ hydrogen peroxide. For monoclonal antibody bcl-2 and c-myc (concentration of $1 \mu \mathrm{g} / \mathrm{mL}$ ) incubation with primary antibody was carried out overnight at $4^{\circ} \mathrm{C}$. Sections of bcl-2 positive lymphoid tissue were used as positive controls. Sections of c-myc positive lung carcinoma were used as positive controls. For negative controls, the samples were taken through the procedure with omission of the primary antibody. Slides were evaluated by two of the authors, unaware of immunohistochemical or clinical data using a semiquantitative method on a Zeiss AXIOSKOP 2 light microscope. The percentage of immunopositive cells in representative areas of the sections was assessed. The intensity of immunostaining was divided into 4 categories, namely i) negative $(0-5 \%)$ and ii) $1+(5-25 \%)$; iii) positive $2+(25-50 \%)$ and iv) $3+(50-100 \%)$. Tissue sections from the operative material or material taken by biopsy were taken after obtaining informed consent of patients in accordance with the Declaration of Helsinki and recommendations of the World Health Organization (WHO) for experiments on human material and after getting approval of the Ethics Committee.

\section{Statistics}

Based on the frequency of the lesions found, patients were split into 4 subgroups and $2 \times 2$ contingency tables were formed and specificity and sensitivity were calculated. Also, based on the receiver operating characteristic (ROC) curve, which represents the relation between specificity and sensitivity, the discrimination power of the test was determined. Differences between groups were considered significant (Fisher's exact test) at $\mathrm{P}<0.05$. By establishing sensitivity and specificity of the test, the reliability of these analyses, could be the subject of scientific investigation as one of the factors in the prognosis of premalignant lesions of the uterine cervix, in the course of future researches.

\section{Results}

Table 1 and Figure 1 show the expression levels of bcl-2 oncogene in the study and control group. Overexpression of bcl-2 was present in $5.6 \%$ (mean $\pm \mathrm{SD}=9.61 \pm 13.27$ ) of women in the control group and in $25.0 \%$ (mean $\pm \mathrm{SD}=$ $20.44 \pm 27.69$ ) (of patients with low grade SIL. Analysis of frequency of patients with positive findings of bcl-2 oncogene revealed no statistical differences when control and low grade SIL groups were evaluated (Fisher's exact test, $\mathrm{P}=0.164$ ). On the basis of the frequency of patients with bcl- 2 overexpression, a $2 \times 2$ table of contingency was formed (Table 2 ), in which sensitivity and specificity were calculated. The sensitivity of determining bcl- 2 as a method

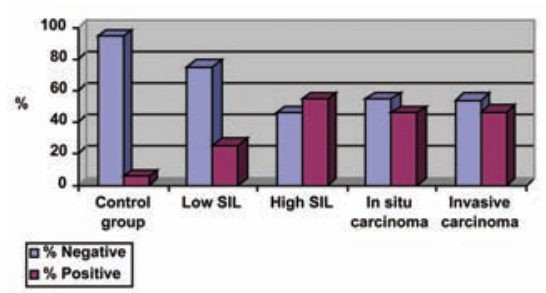

Figure 1. Percentage of positive and negative bcl- 2 expression.

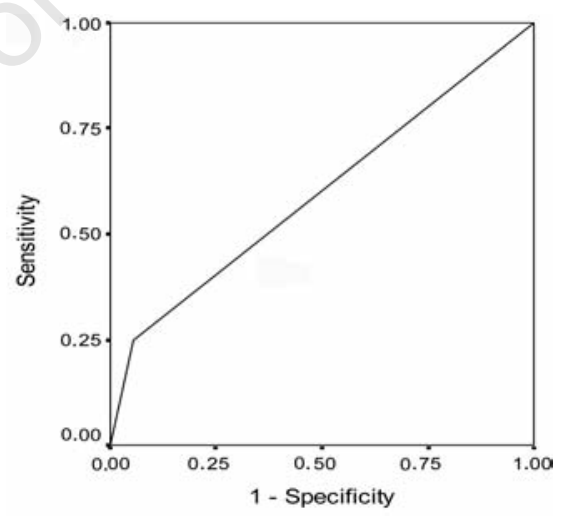

Figure 2. Receiver operating characteristic curve for bcl-2 overexpression in patients with low grade squamous intraepithelial lesions.

Table 1. Expression of bcl-2 in the control and study groups.

\begin{tabular}{lccccc}
$\begin{array}{l}\text { bcl-expression } \\
\text { expression }\end{array}$ & $\begin{array}{c}\text { Control } \\
\text { group, } \\
\text { n (\%) }\end{array}$ & $\begin{array}{c}\text { Low girade } \\
\text { SIL, } \\
\text { n (\%) }\end{array}$ & $\begin{array}{c}\text { High grade } \\
\text { SIL, } \\
\text { n (\%) }\end{array}$ & $\begin{array}{c}\text { PVU in situ } \\
\text { carcinoma, } \\
\text { n (\%) }\end{array}$ & $\begin{array}{c}\text { PVU invasive } \\
\text { carcinoma, } \\
\text { n (\%) }\end{array}$ \\
Negative (-) & $20 / 36(55.5)$ & $16 / 32(50)$ & $8 / 22(36.3)$ & $8 / 22(36.3)$ & $8 / 26(30.8)$ \\
Negative (1+) & $14 / 36(38.9)$ & $8 / 32(25.0)$ & $2 / 22(9.1)$ & $4 / 22(18.2)$ & $6 / 26(23.1)$ \\
\hline Positive (2+) & $2 / 36(5.6)$ & $2 / 32(6.2)$ & $8 / 22(36.3)$ & $6 / 22(27.3)$ & $8 / 26(30.8)$ \\
Positive (3+) & $0 / 36(0)$ & $6 / 32(18.8)$ & $4 / 22(18.2)$ & $4 / 22(18.2)$ & $4 / 26(15.3)$ \\
\hline
\end{tabular}

SIL, squamous intraepithelial lesions; $\mathrm{PVU}$, portio vaginalis uteri.

Table 2. Table of contingency (low grade squamous intraepithelial lesions).

\begin{tabular}{lccc} 
Test & $\begin{array}{c}\text { Disease present } \\
\text { (low grade SIL) }\end{array}$ & $\begin{array}{c}\text { Disease absent } \\
\text { (control group) }\end{array}$ & Total \\
bcl-2 overexpression & $8(\mathrm{P}=0.164)$ & 2 & 10 \\
bcl-2 negative & 24 & 34 & 58 \\
\hline Total & 32 & 36 & 68
\end{tabular}

SIL, squamous intraepithelial lesions. 
patients with bcl-2 negative expression existence of this type of change is not expected.

Table 1 and Figure 1 show that bcl- 2 overexpression was present in $5.6 \%$ of women in the control group and in $54.6 \%$ (mean $\pm \mathrm{SD}=$ $27.27 \pm 21.89$ ) of patients with high grade SIL (Fisher's exact test, $\mathrm{P}=0.006$; Figure 3 ). The sensitivity of determining bcl-2 for detecting high grade SIL changes was $54.6 \%$ and specificity was 94.4\% (Table 3 and Figure 4).

Regarding the obtained values of sensitivity and specificity, the discrimination power of overexpression of this oncogene with the aim of determining the existence of changes of this type was greater than the discrimination power of negative expression in the control group. The positive predictive value in high grade SIL changes was $85.89 \%$ and the negative predictive value was $77.21 \%$.

Table 1 and Figure 1 show that bcl- 2 overexpression was present in $5.6 \%$ of patients in the control group and in $45.5 \%$ (mean $\pm \mathrm{SD}=$ $6.27 \pm 7.04$ ) of patients with PVU carcinoma in situ (Fisher's exact test, $\mathrm{P}=0.018$; Figure 5). The sensitivity of this oncogene for diagnosing this type of lesions was $45.5 \%$ and specificity was $94.2 \%$ (Table 4 and Figure 6 ). The positive predictive value was $74.64 \%$ and the negative

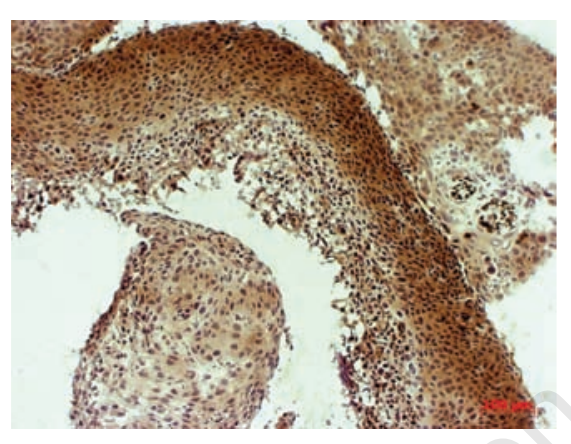

Figure 3. Bcl-2 overexpression (3+) in high grade squamous intraepithelial lesions.

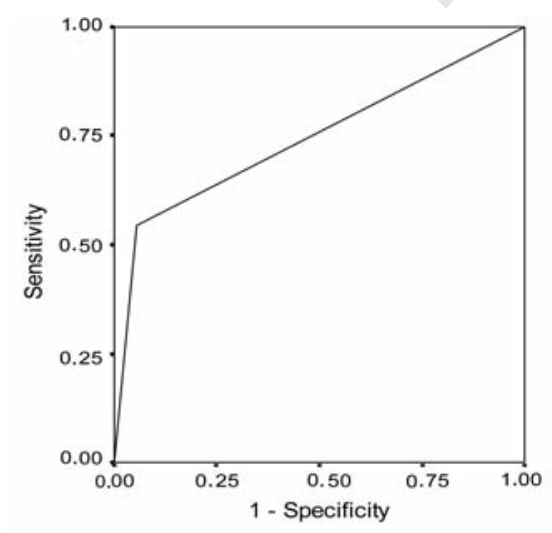

Figure 4. Receiver operating characteristic curve for bcl-2 overexpression in patients with high grade squamous intraepithelial lesions. predictive value was $67.98 \%$. Table 1 and Figure 1 show that bcl-2 overexpression was present in $5.6 \%$ of patients in the control group and in $46.1 \%($ mean $\pm \mathrm{SD}=22.15 \pm 23.99)$ of patients with PVU invasive carcinoma (Fisher's exact test, $\mathrm{P}=0.012$; Figure 7). The sensitivity and specificity of the test were $46.2 \%$ and $94.4 \%$, respectively (Table 5 and Figure 8 ), and the positive and negative predictive values were $85.84 \%$ and $70.80 \%$, respectively. Table 6 and Figure 9 show co-expression levels of bcl-2 and c-myc oncogenes in the control and in the experimental group (6/26-

Table 3. Table of contingency (high grade squamous intraepithelial lesions).

\begin{tabular}{lccc} 
Test & $\begin{array}{c}\text { Disease present } \\
\text { (high grade SIL) }\end{array}$ & $\begin{array}{c}\text { Disease absent } \\
\text { (control group) }\end{array}$ & Total \\
bcl-2 overexpression & $12(\mathrm{P}=0.006)$ & 2 & 14 \\
bcl-2 negative & 10 & 34 & 44 \\
\hline Total & 22 & 36 & 58 \\
\hline
\end{tabular}

SIL, squamous intraepithelial lesions.

Table 4. Table of contigency (portio vaginalis uteri carcinoma in situ).

\begin{tabular}{lccc} 
Test & $\begin{array}{c}\text { Disease present } \\
\text { (PVU carcinoma in situ) }\end{array}$ & $\begin{array}{c}\text { Disease absent } \\
\text { (control group) }\end{array}$ & Total \\
bcl-2 overexpression & $10(\mathrm{P}=0.018)$ & 2 & 12 \\
bcl-2 negative & 12 & 34 & 46 \\
\hline Total & 22 & 36 & 58 \\
\hline
\end{tabular}

PVU, portio vaginalis uteri.

Table 5. Table of contingency (portio vaginalis uteri invasive carcinoma).

\begin{tabular}{lccc}
\hline Test & $\begin{array}{c}\text { Disease present } \\
\text { (PVU invasive carcinoma) }\end{array}$ & $\begin{array}{c}\text { Disease absent } \\
\text { (control group) }\end{array}$ & Total \\
bcl-2 overexpression & $12(\mathrm{P}=0.012)$ & 2 & 14 \\
bcl-2 negative & 14 & 34 & 48 \\
\hline Total & 26 & 36 & 62
\end{tabular}

$\mathrm{PVU}$, portio vaginalis uteri.

Table 6. Co-expression of bcl-2 and c-myc in the control and study groups.

\begin{tabular}{lccccc}
$\begin{array}{l}\text { bcl-2 and c-myc } \\
\text { co-expression }\end{array}$ & $\begin{array}{c}\text { Control } \\
\text { group, } \\
\text { n (\%) }\end{array}$ & $\begin{array}{c}\text { Low grade } \\
\text { SIL, } \\
\text { n (\%) }\end{array}$ & $\begin{array}{c}\text { High grade } \\
\text { SIL, } \\
\text { n (\%) }\end{array}$ & $\begin{array}{c}\text { PVU in situ } \\
\text { carcinoma, } \\
\text { n (\%) }\end{array}$ & $\begin{array}{c}\text { PVU invasive } \\
\text { carcinoma, } \\
\text { n (\%) }\end{array}$ \\
Negative (-) & $28 / 36(77.8)$ & $24 / 32(75)$ & $16 / 22(72.8)$ & $18 / 22(81.9)$ & $12 / 26(46.2)$ \\
Negative (1+) & $8 / 36(22.2)$ & $8 / 32(25.0)$ & $6 / 22(27.2)$ & $4 / 22(18.1)$ & $8 / 26(30.8)$ \\
\hline Positive (2+) & $0 / 36(0)$ & $0 / 32(0)$ & $0 / 22(0)$ & $0 / 22(0)$ & $2 / 26(7.7)$ \\
Positive (3+) & $0 / 36(0)$ & $0 / 32(0)$ & $0 / 22(0)$ & $0 / 22(0)$ & $4 / 26(15.3)$
\end{tabular}

SIL, squamous intraepithelial lesions; $\mathrm{PVU}$, portio vaginalis uteri.

Table 7. Table of contingency (portio vaginalis uteri invasive carcinoma).

\begin{tabular}{lccc} 
Test & $\begin{array}{c}\text { Disease present } \\
\text { (PVU invasive carcinoma) }\end{array}$ & $\begin{array}{c}\text { Disease absent } \\
\text { (control group) }\end{array}$ & Total \\
bcl-2 and c-myc co-overexpression & $6(\mathrm{P}=0.064)$ & 0 & 6 \\
bcl-2 and c-myc negative & 20 & 36 & 56 \\
\hline Total & 26 & 36 & 62 \\
\hline
\end{tabular}

PVU, portio vaginalis uteri. 
sensitivity of determining this oncogene with the aim of detecting PVU invasive carcinoma was $23 \%$ while specificity was $72.2 \%$. On the basis of the frequency of patients with bcl-2 and c-myc co-overexpression, a $2 \times 2$ table of contingency was formed in which sensitivity and specificity was calculated (Table 7). 0n the basis of the obtained values of sensitivity and specificity, discrimination power of negative expression in patients with normal findings in the cervix was greater than discrimination power of co-overexpression of this oncogene, with the aim of determining the existence of change of this type (Figure 11). The positive predictive value was $100 \%$ which, statistical wise, means that PVU invasive carcinoma may be expected in all patients with cooverexpression of bcl-2 and c-myc. However, the substantiation of the claim requires much more extensive research. The negative predictive value was $64.34 \%$, implying that the existence of this type of change is not expected at this percentage of patients with negative coexpression of bcl-2 and c-myc oncogene.

\section{Discussion}

This study evaluated the expression of bcl-2 and c-myc oncogenes in a range of tissues obtained from normal, dysplastic and neoplastic conditions of the cervix, in an attempt to elucidate the expression of this oncoprotein in uterine cervix premalignant and malignant lesions. Bcl-2 is an oncogene that has been investigated for prognostic significance in various malignancies, including carcinoma of the cervix. ${ }^{16-18}$ Up to now, conflicting results have been obtained. Bcl-2 has been shown in some studies to be an independent predictor of poor prognosis in carcinoma of the cervix..$^{19}$ On the other hand, other studies have revealed no statistically significant correlation with adverse outcome. ${ }^{20}$

The conflicting results may be due to differences in institutional treatment standards and to varied subjective interpretations of staining intensity and distribution between centers. Since staining is judged on a continuum, differences in institutional cut-off determinations for positive staining may also affect the correlation with clinicopathological results.

Cheung et al., in their analysis of 44 patients with cervical adenocarcinoma, found that increased expression of bcl- 2 was correlated with a poorer prognosis. ${ }^{21}$ The absence of correlation between clinical prognosis and bcl2 expression was instead described by Jain $e t$ $a l .^{22}$ In our study, no statistically significant difference was found in the frequency of overexpression of bcl-2 between the control group and patients with low grade SIL. However, sta- tistically significant difference was found in the frequency of overexpression in patients with high grade SIL, PVU carcinoma in situ and PVU carcinoma invasive in relation to the control group. High sensitivity values speak in favor of great diagnostic significance for the detection of these types of changes in the uterine cervix. On the basis of high predictive values, it can be said that, in patients with overexpression of bcl-2 oncogene, there is a great possibility that they have premalignant or malignant changes in the uterine cervix.

The c-myc oncogene is known to regulate

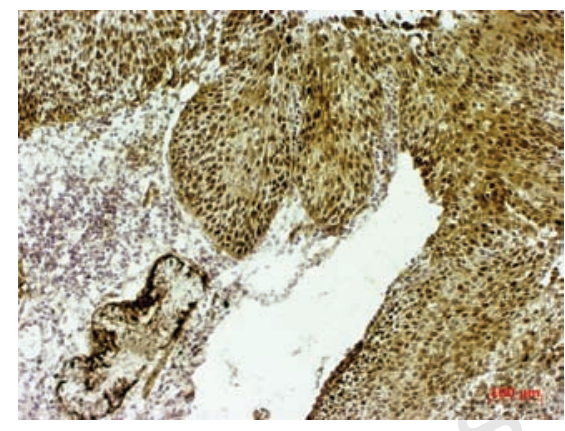

Figure 5. Bcl-2 overexpression (3+) in portio vaginalis uteri carcinoma in situ.

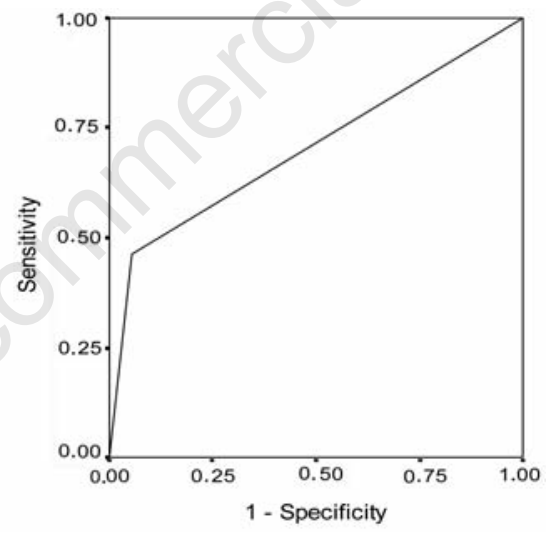

Figure 6. Receiver operating characteristic curve for bcl-2 overexpression in patients with portio vaginalis uteri carcinoma in situ.

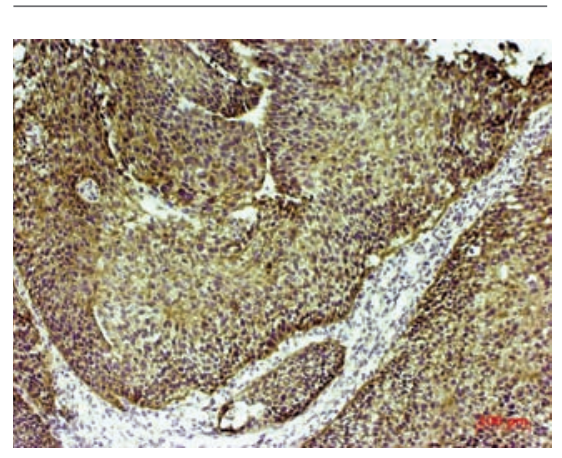

Figure 7 . bcl-2 overexpression (3+) in portio vaginalis uteri invasive carcinoma.

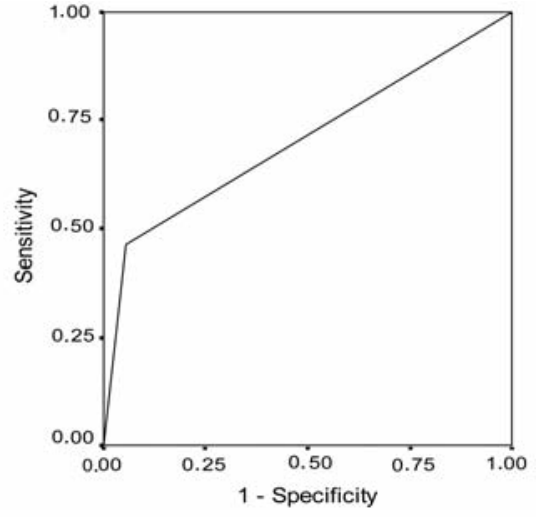

Figure 8. Receiver operating characteristic curve for bcl-2 overexpression in patients with portio vaginalis uteri invasive carcinoma.

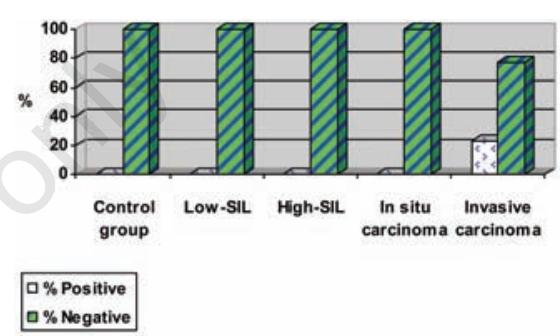

Figure 9. Percentage of positive and negative bcl-2 and c-myc co-expression.

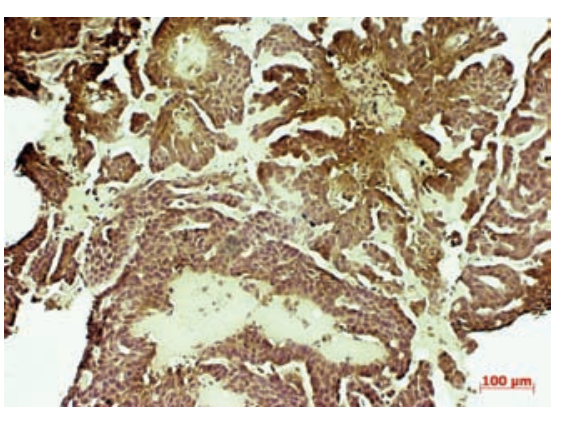

Figure 10. C-myc overexpression (3+) in portio vaginalis uteri invasive carcinoma.

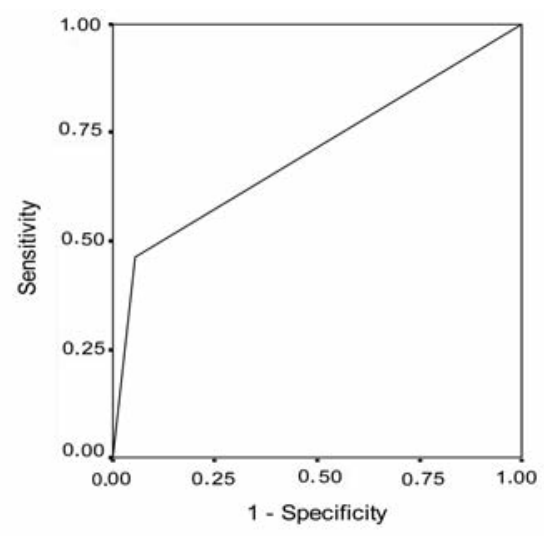

Figure 11. Receiver operating characteristic curve for bcl-2 and c-myc co-overexpression in patients with portio vaginalis uteri invasive carcinoma. 
neoplastic development and apoptotic cell death. Myc protein is widely distributed in different tissues and is predominantly localized to nuclei of cells where its positivity related to proliferation rate..$^{23}$

Bcl-2 at high concentrations protects cells apoptosis induced by c-myc. However, the associations of these proteins and the correlation of their expression and the prognosis of cancer are still controversial. Cooperation between cmyc and bcl-2 in the lymphoid tumors has been demonstrated in double transgenic mice. ${ }^{24}$

Jinyoung et al. found that overexpression of c-myc and bcl-2 plays a role as prognostic factor in pulmonary adenocarcinomas. ${ }^{25}$

The positive role of c-myc in promoting cell proliferation places this oncogene at the head of bcl-2 partners for metastatic progression and lymph node involvement of small and well differentiated breast tumors, because bcl- 2 may also act as an effective suppressor of the apoptotic action of c-myc, without affecting its ability to promote cell proliferation. ${ }^{26}$ Liu et al. noted a significant positive relationship between bcl-2 and c-myc in female genital tract sarcomas. ${ }^{27}$

In our study, co-overexpression of bcl-2 and c-myc oncogenes was found only in patients with PVU invasive carcinoma (3/13-23.0\%). Analysis of frequency of patients with positive findings of bcl-2 and c-myc, revealed no statistical significant differences $(\mathrm{P}=0.064)$ when control and PVU invasive carcinoma groups were evaluated. The method's sensitivity of determining this oncogenes with the aim of detecting PVU invasive carcinoma was $23 \%$ and specificity was $72.2 \%$. On the basis of the obtained values of sensitivity and specificity, discrimination power of negative expression in patients with normal findings in the cervix was greater than discrimination power of cooverexpression of these oncogenes with the aim of determining the existence of change of this type.

On the basis of high predictive values, it can be concluded that, statistical wise, all patients with co-overexpression of bcl-2 and c-myc oncogenes will have PVU invasive carcinoma.

\section{Conclusions}

The findings presented in this study indicate that the evaluation of co-expression of bcl2 and c-myc may provide additional and independent prognostic information to predict the clinical course of cervical cancer. In our study we confirmed that co-overexpression of these oncogenes suggests with great certainty, at least statistically, that there are malignant changes in the uterine cervix. However, a more extensive series of samples and additional tests are required to establish the prognostic significance of co-expression of bcl- 2 and cmyc in uterine cervix carcinogenesis.

\section{References}

1. Zha J, Harada H, Osipov K, Jockel J, Waksman G, Korsmayer SJ. BH3 domain of $\mathrm{BAD}$ is required for heterodimerization with Bcl-X(L) and pro-apoptotic activity. J Biol Chem 1997;272:24101-4.

2. Protrka Z, Djuric J, Protrka 0, Arsenijevic $\mathrm{S}$. The possible role of bcl-2 expression of tumors of the uterine cervix. J BUON 2010;15:323-9.

3. Gross A, McDonnell JM, Korsmeyer SJ. BCL-2 family members and the mitochondria in apoptosis. Genes Dev 1999;13:1899911.

4. Schlesinger PH, Gross A, Yin XM, Yamamoto K, Satto M, Waksman G et al. Comparison of the ion channel characteristics of proapoptotic BAX and antiapoptotic BCL-2. Proc Natl Acad Sci USA 1997;94: 11357-62.

5. Tjalma WA, Weyler JJ, Bogers JJ, Pollefliet CX, Baay M, Goovaerts GC, et al. The importance of biological factors (bcl-2, bax, p53, PCNA, MI, HPV and angiogenesis) in invasive cervical cancer. Eur J Obstet Gynecol Reprod Biol 2001;97:22330 .

6. Boise LH, Gonzalez-Garcia M, Postema CE, Ding L, Lindsten T, Turka LA et al. Bcl-x, a $\mathrm{Bcl}-2$-related gene that functions as a dominant regulator of apoptotic cell death. Cell 1993;74:597-608.

7. Vander Heiden MG, Chandel NS, Schumacker PT, Thompson CB. Bcl-x(L) prevents cell death following growth factor withdrawal by facilitating mitochondrial ATP/ADP exchange. Mol Cell 1999;3:15967.

8. Jansen-Durr P, Meichle A, Steiner P, Pagano M, Finke K, Botz J, et al. Differential modulation of cyclin gene expression by Myc. Proc Natl Acad Sci USA 1993;90: 3685-9.

9. Lee LA, Dolde C, Barrett J, Wu Cs, Dang CV. A link between c-Myc-mediated transcriptional repression and neoplastic transformation. J Clin Investig 1996;97: 1687-95.

10. Loke S, Neckers LM, Schwab G, Jafee ES. $\mathrm{C}$-myc protein in normal tissue. Effects of fixation on its apparent subcellular distribution. Am J Pathology 1988;131:29-37.

11. Meichle A, Philipp A, Eilers M. The function of Myc proteins. Biochem Biophys Acta 1992;1114:129-46.

12. Nair SA, Nair MB, Jayaprakash PG,
Rajalekshmy TN, Nair MK, Pillai MR. Ras and c-myc oncoproteins during tumor progression in uterine cervix. Tumori 1998;84:583-8.

13. Golijow CD, Abba MC, Mouron SA, Gomez MA, Dulout FN. C-myc gene amplification detected in preinvasive intraepithelial cervical lesions. Int J Gynecol Cancer 2001; 11:462-5.

14. Brenna SMF, Zeferino LC, Pinto GA. C-Myc protein expression 154 is not an independent prognostic predictor in cervical squamous cell carcinoma. Braz J Med Biol Med Res 2002;35:425-30.

15. Zanotti S, Fisseler-Eckhoff A, Mannherz HG. Changes in the topological expression of markers of differentiation and apoptosis in defined stages of human cervical dysplasia and carcinoma. Gynecol Oncol 2003; 89:376-84.

16. Skirnisdottir I, Seidal T, Gerdin E, Sorbe B. The prognostic importance of p53, Bcl-2, And bax in early stage epithelial ovarian carcinoma treated with adjuvant chemotherapy. Int J Gynecol Cancer 2002; 12:265-76.

17. Nunez G, London L, Hockenbery D, Alexander M, McKearn JP, Korsmeyer SJ. Deregulated Bcl-2 expression selectively promotes survival of growth factordeprived hematopoietic cell lines. J Immunol 1990;144:3602-10.

18. Oltvai ZN, Milliman CL, Korsmeyer SJ. Bcl2 heterodimerizes in vivo with a conserved homolog, Bax, that accelerates programmed cell death. Cell 1993;74:609-19.

19. Chung TK, Cheung TH, Lo WK, Yu My, Krajewski S, Reed JC et al. Expression of apoptotic regulators and their significance in cervical cancer. Cancer Lett 2002; 180:63-8.

20. Cheah PL, Looi LM. Significance of Bcl-2 and Bax proteins in cervical carcinogenesis: an immunohistochemical study in squamous cell carcinoma and squamous intraepithelial lesions. Malays J Pathol 2006;28:1-5.

21. Cheung TH, Chung TK, Lo KW, Yu My, Krajewski S, Reed JC et al. Apoptosis-related proteins in cervicalintraepithelial neoplasia and squamous cell carcinoma of the cervix. Gynecol Oncol 2002;86:14-8.

22. Jain D, Srinivasan R, Patel FD, Kumari Gupta S. Evaluation of p53 and Bcl-2 expression as prognostic markers in invasive cervical carcinoma stage IIb/III patients treated by radiotherapy. Gynecol Oncol 2003;88:22-8.

23. Pelengaris S, Khan M, Evan G. C-myc: more than just a matter of life and death. Nat Rev Cancer 2002;7:764-76.

24. Strasser A, Harris AW, Bath ML, Cory S. Novel primitive lymphoid tumours induced 
in transgenic mice by cooperation between Myc and bcl-2. Nature 1990;348:331-3.

25. Yoo J, Jung JH, Choi HJ, Kang SJ, Kang CS. The expression of c-myc, bcl-2 and p53 proteins in adenocarcinomas of lung.
Cancer Res Treat 2004;36:146-50.

26. Sierra A, Castellsague X, Escobedo A, Moreno A, Drudis T, Fabra A. Synergistic cooperation between c-myc and bcl-2 in lymph node progression of $\mathrm{T} 1$ human breast carcinomas. Breast Cancer Res
Treat 1999;54:39-45.

27. Liu FS, Jan YJ, Lai CR, Twu NF, Lu CH, Hung MJ et al. Expression analysis of apoptosis-related markers TP53, bcl-2, BAX and c-myc in female genital tract sarcomas. J Chin Med Assoc 2008;71:628-34. 